\title{
Knee Pain and Swelling Secondary to Ulcerative Colitis
}

\author{
Shogo Yanagisawa Masahiko Inamori Hiroki Endo Hiroshi lida Keiko Akimoto \\ Yasunari Sakamoto Tomoyuki Akiyama Koji Fujita Masato Yoneda Hirokazu Takahashi \\ Yasunobu Abe Noritoshi Kobayashi Hiroyuki Kirikoshi Kensuke Kubota Norio Ueno \\ Atsushi Nakajima
}

Gastroenterology Division, Yokohama City University School of Medicine, Yokohama, Japan

\section{Dear Sir,}

A 32-year-old man was admitted to our hospital because of a 2-week history of episodic bilateral knee pain and fever $\left(38.5^{\circ} \mathrm{C}\right)$. Physical examination of the patient's knees revealed moderate effusion (right $>$ left), normal appearance of the overlying skin, mild warmth to touch, and a decreased range of motion secondary to pain and swelling. Laboratory data obtained at that time revealed severe anemia (hemoglobin $5.9 \mathrm{~g} / \mathrm{dl}$, hematocrit $18.2 \%$, C-reactive protein $18.6 \mathrm{mg} / \mathrm{dl}$ ). Phenotyping for human leukocyte anti- gen B27 and testing for antinuclear antibody and rheumatoid factor were negative. Colonoscopy revealed multiple erosions in colon and rectum, and the biopsy findings were compatible with a diagnosis of ulcerative colitis. We made a diagnosis of ulcerative colitis with secondary peripheral arthritis, and prednisolone therapy was started (60 mg/day). The knee pain soon decreased, and 2 months after the start of the prednisolone therapy, the patient was discharged without anemia or knee pain.
A link between peripheral arthritis and inflammatory bowel disease has been established in Western countries, and the knee is the most commonly affected joint. Our patient was initially admitted to the orthopedic surgery department with knee pain and swelling, and thus it is important to be aware that, although rarely, inflammatory bowel disease patients sometimes present with peripheral arthritis and only later complain of gastrointestinal symptoms.

Fig. 1. Moderate effusion of the patient's knees (right $>$ left).

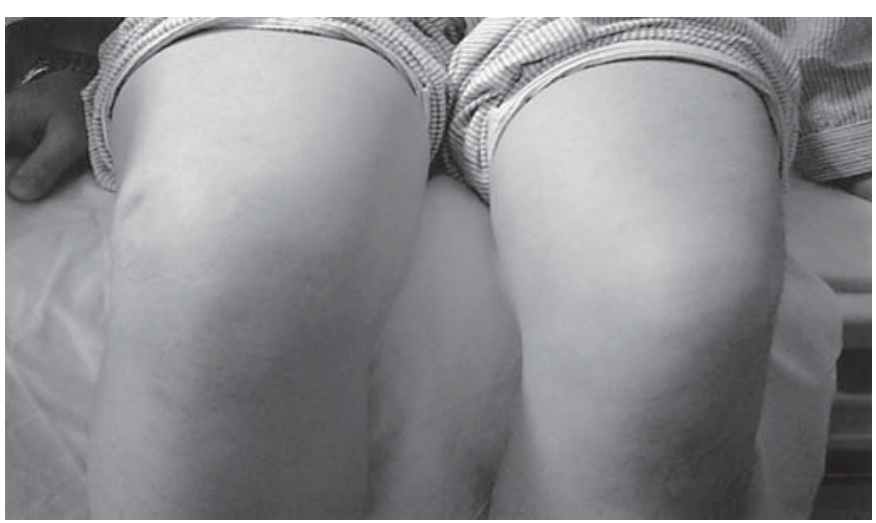

\section{KARGER \\ Fax +41613061234 \\ E-Mail karger@karger.ch}

www.karger.com (c) 2007 S. Karger AG, Basel 0012-2823/07/0753-0144\$23.50/0

Accessible online at: www.karger.com/dig
Masahiko Inamori

Gastroenterology Division, Yokohama City University School of Medicine

3-9 Fukuura, Kanazawa-ku

Yokohama 236-0004 (Japan)

Tel. +81 45787 2640, Fax +81 45784 3546, E-Mail inamorim@med.yokohama-cu.ac.jp 